\title{
Wi-Call : use LAN for calling
}

\author{
Rohit Sen ${ }^{1}$, Nadeem Sajjad ${ }^{2}$, Rahul Kumar Chaurasiya ${ }^{3}$ \\ ${ }^{I}$ (Research Scholar Mewar University Chittorgarh, Rajasthan, India \\ ${ }^{2}$ (Pursuing M.Tech. Mewar University Chittorgarh, Rajasthan, India \\ ${ }^{3}$ (B.Tech. Mewar University, Rajasthan, India
}

\begin{abstract}
In the present day the use of Wi-Fi in mobile devices is increasing day by day. Everyone has Wi-Fi enabled device, and these Wi-Fi enable devices work as IP phones, how these devices communicate with each other over Wi-Fi LAN is discussed in this paper. It is the type of telecommunication which allows voice call and data transmission across the various interconnected devices. A device which is Wi-Fi enabled and have this app can communicate with each other through the $2.4 \mathrm{GHz}$ UHF radio waves. We are using radio waves for communication there is no costing to make a call and data transmission so it is free. Model is limited to the local WLAN network so it is secured from bypassing data through different server. This model is not using any bandwidth of internet so we are not dependent on internet accessibility to do our work.

For sending the packets of data it follow the IP ESP (Encapsulating Security Payload) for make our data confidential. Each mobile devices connects to a WLAN router can connect to each other by a local web service which is run on server here all the information of user is being kept here, User identify itself and other user which he wish to connect. This model is proposed for reduce the communication cost of large organization.
\end{abstract}

Keywords: - free LAN calling, Wi-Fi Call, Wi-Call

\section{INTRODUCTION}

Communication System are changing the way we do business and the way we live .Wireless LANs(WLAN) are rapidly becoming pervasive among enterprises. Mobile devices play the powerful role in communication .Every fond of these devices and the use of these device are increasing day by day new features is been added into this instrument. We are going to implement wireless IP phone communication using Wi-Fi network.

Basically our target area is an organization such as offices, school, colleges etc. For making a call into the organization like in a particular department we have to take the service of licensed service provider like BSNL, Vodafone. Reliance it takes a lot of charge for these thing .Our model is to reduce these cost and make it free through the facility of WLAN, it eliminates the need of using the service provider's bandwidth. Now a time every one having Android, IOS , BlackBerry facilities smart phone almost all that type of device having feature of WI-FI, can communicate each other in the network of WLAN. It is work on WLAN so it does not need any Global connection (Internet). The base idea is unifying voice and data onto a single network infrastructure by digitizing the voice signals, convert them into IP packets and send them through an IP network together with the data information, instead of using a separate telephony network.

\section{EXISTING TECHNOLOGY}

Existing technology to making a call is that a VoIP (Voice over Internet Technology). VoIP, or Voice over Internet Protocol, is a method for taking analog audio signals, like the kind you hear when you talk on the phone, and turning them into digital data that can be transmitted.

Over the internet [1] VoIP technologies and applications have led to the development of economical IP phone equipment based on embedded systems. IP phone application can allows audio signal and convert to digital signal works as interface between telephony signal and IP network. We are going to implement wireless communication through IP phone. These application use Generic Access Network (GAN).

Generic Access Network or GAN is a telecommunication system that extends mobile voice, data and multimedia application over IP network. Unlicensed Mobile Access or UMA is the commercial name used by mobile carriers for external IP access into their core networks [2]. The 3GPP GAN standards evolved from an UMA (Unlicensed Mobile Access) specification specify the handling of secure connectivity, registration, and transmission in order to let subscribers make calls inside the home over subscriber's unlicensed spectrum technologies (WLANs) to leverage VoIP over broadband service. Unlicensed mobile access (UMA) telecommunication system includes both licensed and unlicensed radio infrastructure. 


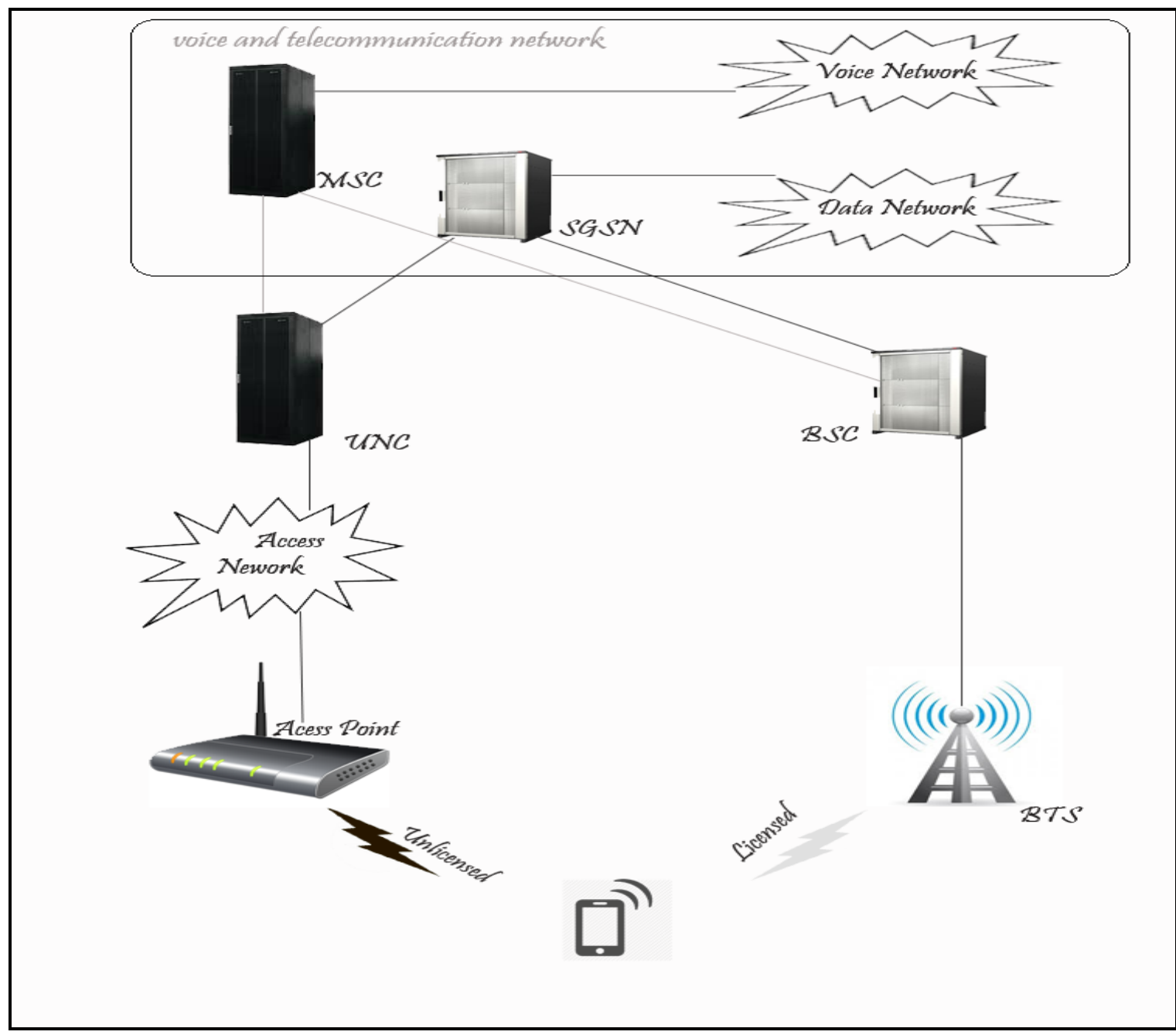

Fig 1 UMA Architecture

UMA architecture enables a user of a mobile station to access a voice and telecommunications block via either a licensed wireless communications session, or an unlicensed wireless communication session. The telecommunications network contain a mobile switching center (MSC), which provides access to a voice network, and a GPRS (General Packet Radio Service) through SGSN, which provides access to a data network. An unlicensed communication session is facilitated via an (wireless) access point (AP). Typically, AP will be found in a fixed structure, such as a home or an organization building. The range of Wi-Fi is fixed; it is limited to a fixed area. The mobile station may be connected to the telecommunications network via a second data path that includes an unlicensed wireless channel, access point, an access network, and an unlicensed mobile access network controller (UNC). The UNC communicates with telecommunications network.

\section{WORKING}

\section{About application}

To communicate with router mobile device needs a platform and follows the networking term .A application can be used in Wi-Fi enabled mobile devices to communicate with router [4]. This application follows the standard in networking and simplified the various process of networking. Application is been made in Android platform, for PC it is made in java. Android gives you a world-class platform for creating apps and games for Android users everywhere, as well as an open marketplace for distributing to them instantly. Android's openness has made it a favorite for consumers. It gives you a single application model that lets you deploy your apps broadly to hundreds of millions of users across a wide range of devices-from phones to tablets and beyond.

The developed application will perform the payload encryption on the transmission side and payload decryption of packets in the receiver side through software manipulations of digital format of data.

When placing the call to a phone within network or request to sending data packets, clients have to select the username which will be display on client application home, those are in range of Wi-Fi region are able to 
communicate each other through placing the call or messages. At the destination end if user is accept the call app changes both phone statuses to busy status. Because conference or conference like feature is not supported by application due to limited bandwidth of $2.4 \mathrm{GHz}$, at busy state no further call can be placed or received by the phone. Once a connection is established and approved the acknowledge data packets will be started to sending and receiving.

\section{Steps to be followed}

1. A web application (run on localhost) will keep the information of users and it only allow registered user for communication. Here users have to register and take user name for further communication.

2. After being registered on webserver, users have own unique username by this they will be identified on network and web application will synchronize the table, will update the new online users.

3. At the home of application users are able to find out online users (which will display with the green bullet), users have to select the target user and to be placed a call or communicate each other, at this state caller and receiver state will be changed to busy state because we have no facility like conference.

4. At the end of call both caller and receiver state will change from busy to active state.

\subsection{Working}

The working of a model is described in fig 2. Figure gives the basic flowchart of the algorithm for Wi-Fi based communication. Algorithm has to be defined for the Android application local web page. The regular 802.11 standards of communication are used for the data transmission.

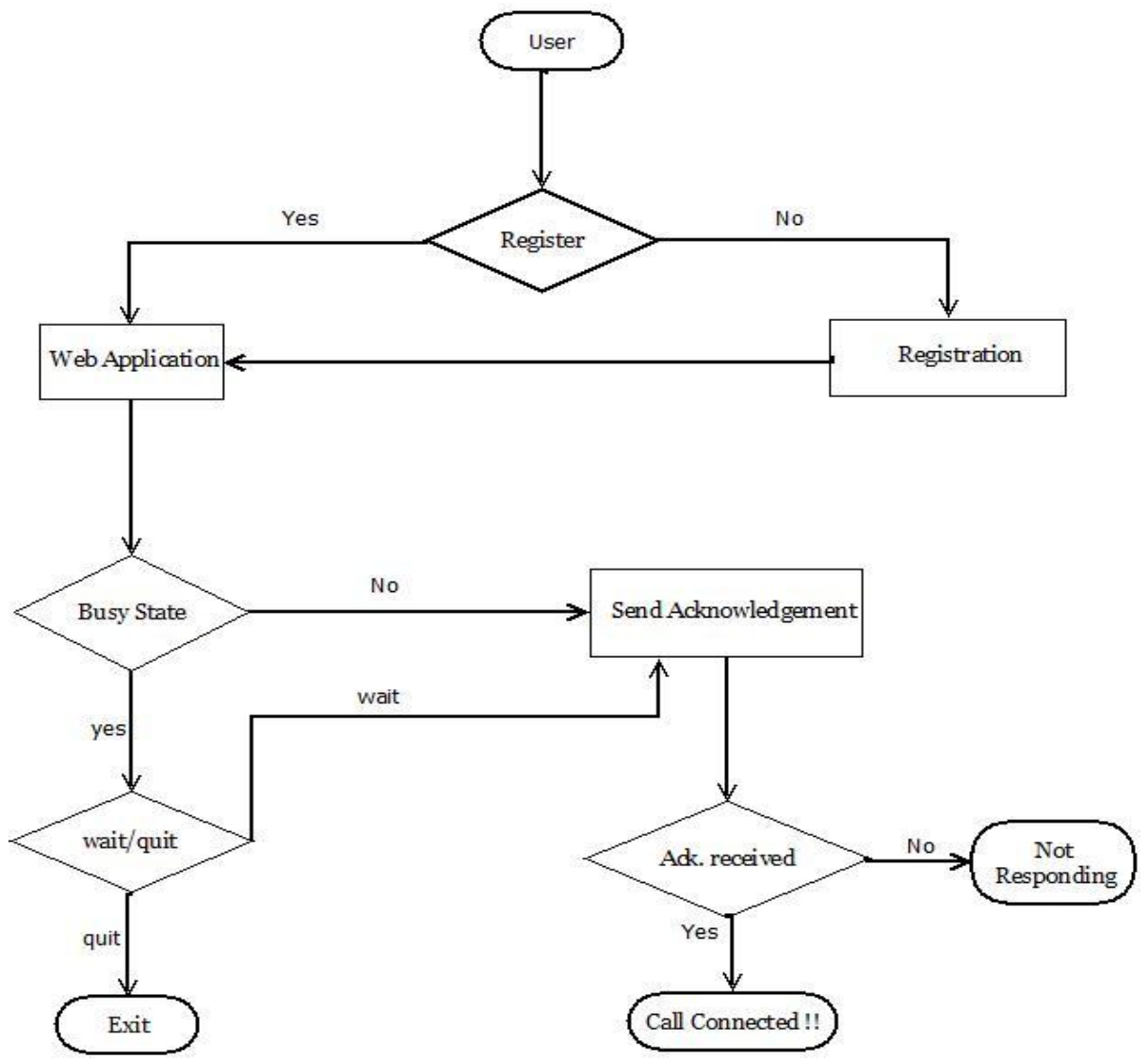

Fig 2 Flowchart describing the overall working of model

There is no need to make any changes in routing table because web application which will be served on local server will manage this entire task. Web service will keep the information of user and help to provide a corresponding IP of the interconnected user. In WLAN network it is hard to maintain a static IP, It is dynamic, it may be possible new user is been assigned the existing user's IP ,in absent of existing user.

To get rid of this problem we implemented a web app, will detect device and corresponding username and IPs. When the IP will change web application update the according to the username.

Process: First user have to register after the registration web application home panel will invoke here all the online user will be showing [5]. For making a call we have to select one of them and make a call but we introduce here a busy flag that means if available user is already on call. We cannot place a call to the busy user 
because busy flag will set to on. At this state we can wait till the call end or can be exit for placing the user call .if flag is off user may send the acknowledgement to the destination user. If target user receive the caller acknowledgement network will be established data packet will start to sending and receiving and both caller and receiver's flag set to busy.

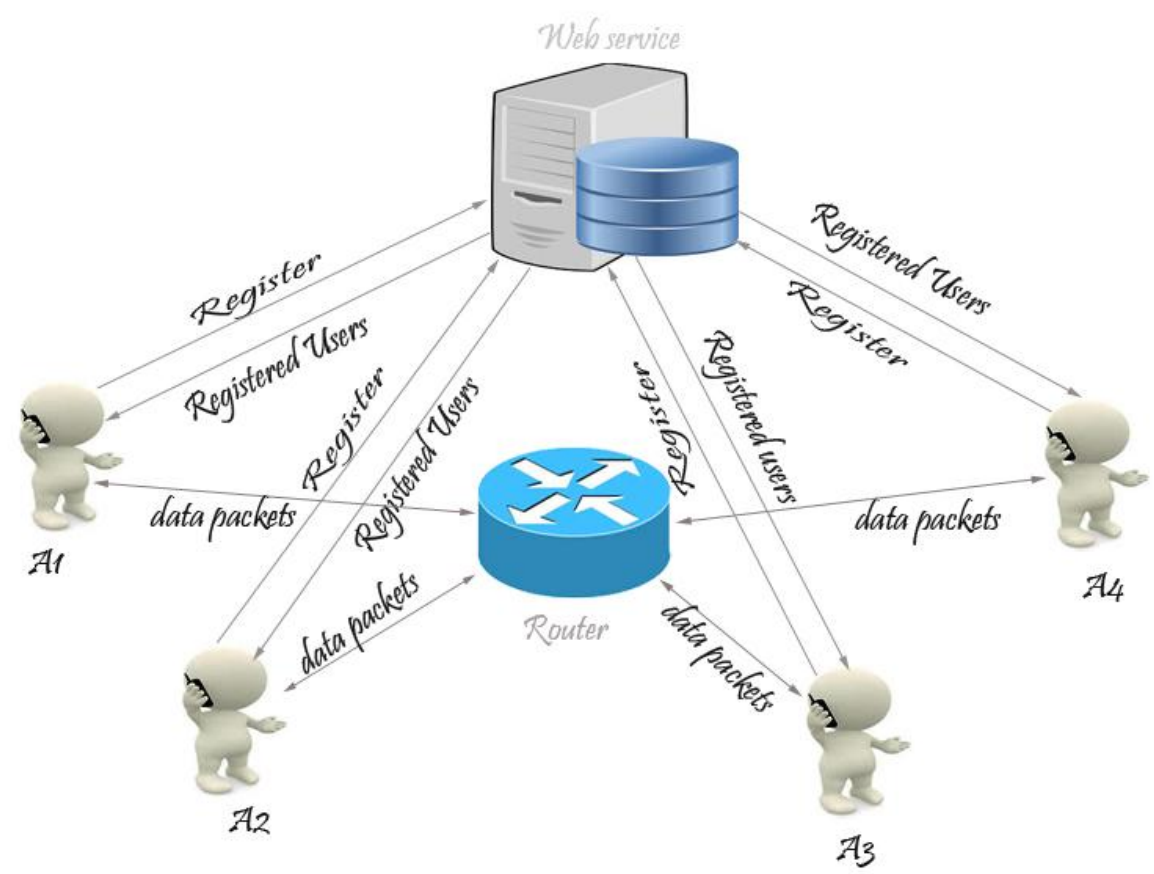

Fig 3 Data Transmission In Model

The figure describes an example where $\mathbf{A 1}, \mathbf{A 2}, \mathbf{A 3}, \mathbf{A 4} \ldots . .$. are the users.

This method of communication is an indirect approach. We know that any number of Wi-Fi enabled phones can access the network. So this ensures that there is no limit to the number of users in the WLAN.

Web application will send the following information of users in network

At A1(A2,A3,A4,IPs)

At A2(A1,A3, A4,IPs)

At A3(A2,A1,A4,IPs)

At A4(A2,A3,A1,IPs)

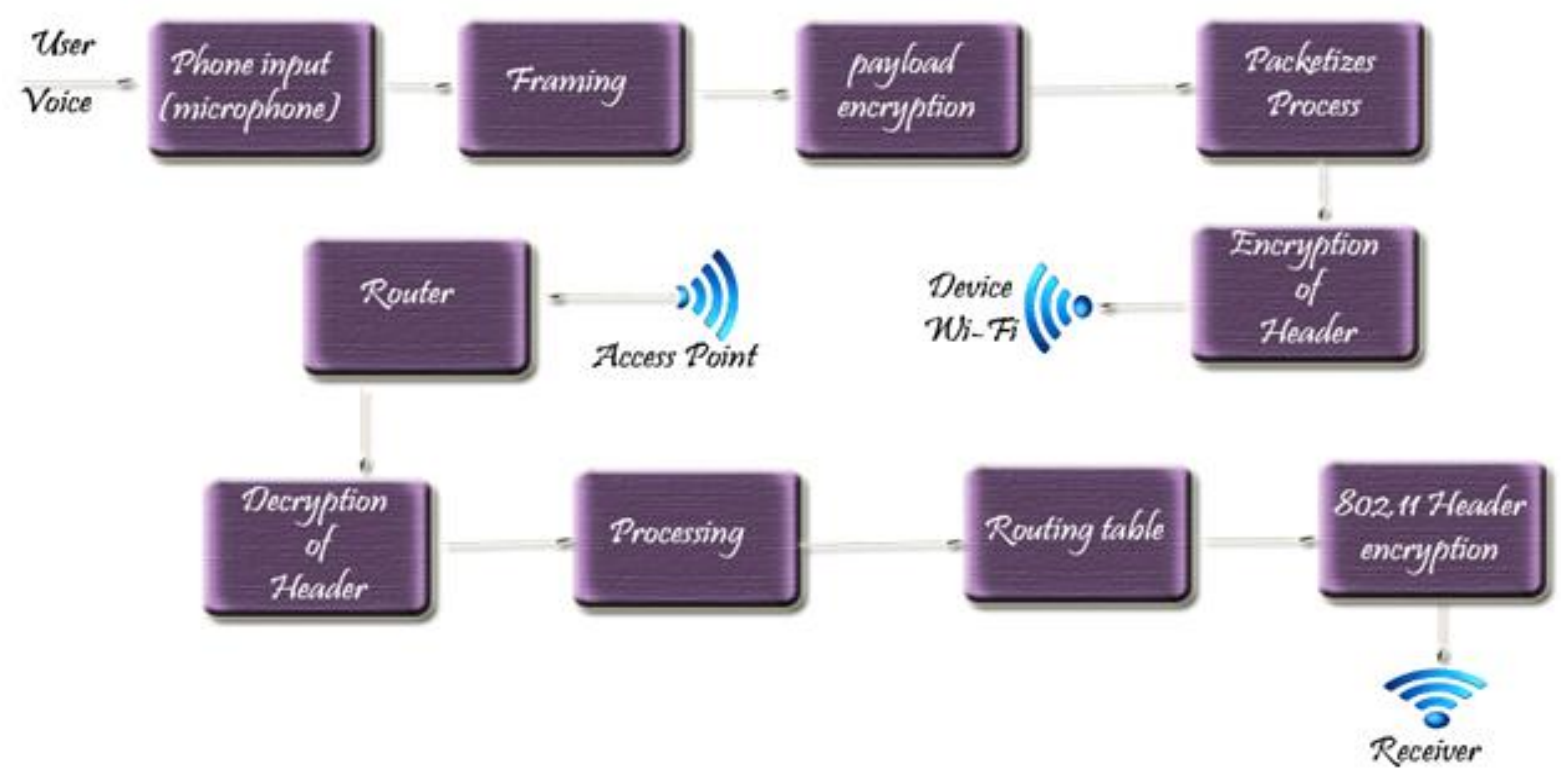

Fig 4 Internal working of devices. 


\section{ADVANTAGES AND LIMITATIONS}

\subsection{Advantages}

- Easy to implement.

- Can be implemented in java providing platform independence.

- It is highly secured because no data is been accessing outside all the data will subject to confidential local web service will be maintain all data.

- Does not require making any changes in routing table.

- Does not require any additional hardware to be installed in the device.

- Utilizing the free bandwidth of $2.4 \mathrm{GHz}$ or higher configure server.

\subsection{Limitations}

Model does not support conference like facility. In poor network it can perform bad, voice legging, interference may be occurred.

\section{CONCLUSION}

Communication over WLAN provides a very good platform to communicate over a local area network. This model provides a basic architecture that can be followed to join the whole organization as currently organizations use basic telephone server which has a limitation that it has only support for landline telephones, while this model will allow devices like mobile phone tablet PC and laptops to communicate. A further data compression technique can be used to allow conference.

\section{ACKNOWLEDGEMENTS}

I feel highly obliged to a few people who have helped and guided me to the correct path from the initiation to the completion of the dissertation work. First of all I would like to thank Mr. B. L. Pal, Head of Department Computer Science and Engineering, Mewar University, Chittorgarh, without whom it would have been a very difficult task. I would also like to thank my guides Mr. Rohit Maheshwari, faculty of Computer Science and Engineering, Mewar University.

\section{REFERENCES}

[1] How VoIP Works, How stuff works , [Online] [Cited: May 5, 2014.] http://computer.howstuffworks.com/ip-telephony.htm.

[2] Generic Access Network, Generic Access Network, [Online] [Cited: May 5, 2014.] http://www.techopedia.com/definition/24977/generic-access-network-gan.

[3] Main and Other Methods, Microsoft Developer Network, [Online] [Cited: May 1, 2014.] http://msdn.microsoft.com/en-us/library/ms228506(v=vs.90).aspx

[4] Wi-Fi, Wi-Fi Alliance, [Online] [Cited: May 5, 2014] http://www.wi-fi.org/

[5] Accessing Databases from Web Applications, Oracle Corporation, [Online] [Cited: April 24, 2014] http://docs.oracle.com/javaee/1.4/tutorial/doc/WebApp6.html 